\title{
¿INVERSIONES CON VIOLENCIA O INVERSIONES PARA LA PAZ?*
}

\author{
Héctor Mondragón**
}

La opinión pública mundial sabe que en Colombia hay un conflicto militar entre distintos "actores armados". Disparan las fuerzas del Estado central, los narcotraficantes, los paramilitares y las guerrillas. Todo esto es muy cierto, pero es sólo la parte más superficial de la verdad, la única que se quiere que el mundo sepa. Si solamente se conoce eso, se perpetuará la tragedia del pueblo colombiano.

Poca gente sabe cuál es el conflicto de fondo que existe en Colombia, el verdadero conflicto. Estamos frente a una segunda Conquista. En la primera, los indígenas fueron despojados de las tierras agrícolas, mientras que los campesinos tuvieron que instalarse en las tierras erosionables de las laderas y junto con las comunidades afroamericanas debieron colonizar las selvas.

Pero parece que los espíritus de los antepasados les jugaron una mala pasada a los conquistadores. Alejados de las mejores tierras agrícolas, los pueblos indígenas, las comunidades afroamericanas y las comunidades de campesinos pobres quedaron ubicados donde están las riquezas de hoy: el petróleo, el gas, los minerales y el agua. En lugares que interesan para los grandes proyectos de inversión: autopistas, proyectos de navegación, canales interoceánicos y fluviales, hidroeléctricas, plantaciones maderables y de palma africana y además, en los sitios donde se puede cultivar la coca y la amapola.

La sociedad dominante tiende cada vez más a una mayor capacidad expansiva a costa de las poblaciones indígenas y de las comunidades locales campesinas y afroamericanas, a las que acosa y devora su territorio y las lleva al deterioro y a la desaparición.

Las transnacionales, los inversionistas golondrina que quieren dinero fácil, el narcotráfico y los especuladores de compra-venta y acumulación de tierras se han abalanzado sobre los territorios de las comunidades y esa es la razón de tanta muerte y tanto desplazamiento. Un millón trescientas mil personas han sido desplazadas de sus tierras en los últimos doce años según las investigaciones realizadas por CODHES en cooperación con la Conferencia Episcopal Colombiana.

Los indígenas apegados a la Madre Tierra se resisten al desplazamiento, pero han tenido que soportar 270 asesinatos desde 1991, cuando el Estado reconoció sus derechos.
Vemos, sin embargo, cómo en los últimos 10 años se ha producido un acelerado proceso de concentración de la tierra en manos de los más grandes propietarios, a la vez que se ha reducido en forma dramática el área sembrada en el país.

La ampliación de área de grandes propiedades dedicadas a la ganadería extensiva es una verdadera relatifundización del país, en la cual la compra de tierras se consolida como un negocio en sí mismo y el precio pagado por las fincas no está determinado por su productividad agropecuaria, sino por las posibilidades de valorización del predio por los megaproyectos.

Puede detectarse el proceso tanto al comparar los resultados de las encuestas agropecuarias, como al comparar los datos registrados en el catastro. Vemos como los grandes propietarios pasaron de tener el $32.5 \%$ de la tierra en 1984 a 35.7 en 1988, a 43.1 en 1996 y $45 \%$ en 1997 :

Cuadro 1

Distribución Fincas: por Superficie y Uso Agrícola según tamaños

\begin{tabular}{|l|rr|rc|rc|}
\hline Tamaño 1988 - 1996* & \multicolumn{2}{|c|}{ \% Fincas } & \multicolumn{2}{|c|}{ \% de Tierra } & \multicolumn{2}{c|}{ \% Uso agricola } \\
& $\mathbf{8 8}$ & $\mathbf{9 6}$ & $\mathbf{8 8}$ & $\mathbf{9 6}$ & $\mathbf{1 9 8 8}$ & $\mathbf{1 9 9 6}$ \\
\hline Muy pequeño (0 a 5 Ha.) & 48.5 & 50.2 & 3.7 & 3.7 & 49.9 & 32.8 \\
\hline Pequeño (5 a 20 Ha.) & 28.5 & 27.8 & 11.4 & 9.9 & 32.9 & 19.8 \\
\hline Mediano (20 a 50 Ha.) & 11.6 & 11.8 & 14.4 & 14.0 & 18.3 & 11.2 \\
\hline Grande (50 a 200 Ha.) & 9.4 & 8.0 & 34.8 & 28.2 & 10.6 & 7.3 \\
\hline Muy Grande (+ de 200) \# & 2.0 & 2.2 & 35.7 & 43.1 & 7.5 & 1.7 \\
\hline
\end{tabular}

* 1996: Pedazos en el Segmento de la Muestra PSM \# 1996: hasta 1.000 Ha. o 1.200 Ha. según Depto.

Fuentes: Ministerio de Agricultura, Penagro, Total Departamentos, p. 36

Fuentes: Ministerio de Agricultura, Penagro,
DANE. Encuesta Nacional Agropecuaria, 1996

Un análisis detenido de la información del catastro muestra que la concentración más fuerte se produce en los predios de más de $2.000 \mathrm{Ha}$.

Hoy, la concentración es más acelerada en Cesar, Bolívar Valle, Quindío, Caquetá y Putumayo, según el IGAC, a lo que habría que agregar, si tenemos en cuenta los datos de las encuestas agropecuarias, Meta Casanare y Chocó.

\footnotetext{
* Este texto es el resultado de una transcripción magnetofónica revisada por la redacción de América Latina Hoy.

** Asesor del Consejo Nacional Campesino y de la Organización Nacional Indígena de Colombia. Delegado de los indígenas en la Secretaría Operativa de la Comisión Nacional de Territorios Indígenas.
} 
Cuadro 2

Distribución de los Predios y sus Superficies según tamaños*

\begin{tabular}{|l|rr|rr|}
\hline \multicolumn{1}{|c|}{ Tamaños Ha. } & \multicolumn{2}{|c|}{ \% Predios } & \multicolumn{2}{c|}{ \% Áreas } \\
& $\mathbf{8 4}$ & $\mathbf{9 7}$ & $\mathbf{8 4}$ & $\mathbf{9 7}$ \\
\hline 0 a 100 & 96,9 & 97,4 & 40,0 & 34,5 \\
\hline 100 a 500 & 2,7 & 2,3 & 27,5 & 20,5 \\
\hline + de 500 & 0,4 & 0,3 & 32,5 & 45,0 \\
\hline
\end{tabular}

* Excluidos departamentos con superficie predominantemente en resguardos indígenas.

Fuente: RINCÓN, Claudia "Estructura de la Propiedad Rural y Mercado de Tierras", Tesis de postgrado U. Nacional, Bogotá 1997, sobre la base de información del IGAC.

Nota: Los datos de las encuestas agropecuarias guardan una coberencia muy gran de con los del catastro y el becho de que en la encuesta de 1996 ( $y$ en la de 1995) el segmento que concentra propiedad conience en las 200 ba. se debe sólo a lo que los técnicos, en estadísticas, llaman "pedazos de unidad de producción en el segmento de la muestra (PSM)" es decir fincas incompletas. Por lo mismo, en la encuesta de 1996 no hay pedazos de más de $1.200 \mathrm{Ha}$. Mientras que los predios del catastro se registran en la totalidad de su tamaño.

La relatifundización se produjo como resultado de la conjunción de fenómenos económicos y políticos:

- La expansión de los grupos armados que han propiciado desplazamientos de población y apoyado procesos de concentración de la propiedad de la tierra en cabeza de narcotraficantes, ganaderos, especuladores y de los mismos dirigentes del paramilitarismo;

- La economía del narcotráfico que produjo, en primer lugar, una nueva capa de compradores de tierra latifundistas, que elevó los costos del dinero y el crédito, fortaleciendo las causas de especulación con la tierra y que, al mismo tiempo, generó una salida económica en las zonas de colonización a parte de los campesinos y jornaleros desplazados por la violencia o por causas económicas;

- La apertura económica que aumentó en 700 \% las importaciones de alimentos y provocó una drástica reducción del área sembrada, especialmente en cereales.

Aunque los cultivos permanentes fueron menos afectados por la crisis agrícola, no absorbieron el área que se dejó de sembrar en transitorios y se produjo, en cambio, una praderización para ganadería extensiva.

Este proceso se verifica en medio de una realidad que está muy lejos de producir el cuadro de reducción de la población rural y en particular, del campesinado, que algunos se imaginaron para el fin del siglo. De este modo, aunque la población rural se ha reducido en términos relativos, ha seguido aumentando en términos absolutos de 6 millones de personas en 1938 a 11,6 millones en 1993.

Otro tanto ha ocurrido con la población económicamente activa del sector agropecuario que pasó de 1,9 millones en 1938 a 2,7 millones en 1993. Aún más, los trabajadores por cuenta propia del sector (campesinos medios) pasaron de 600 mil en 1938 a 700 mil en 1964 y 800 mil en 1993. Desde 1964 se ha reducido, en cambio, y drásticamente, el número de patronos del sector agropecuario, especialmente por la quiebra de los pequeños empresarios. En 1964 había 2,3 trabajadores agropecuarios por cuenta propia por cada empleador, mientras que en 1993 eran 4,7 por cuenta propia por empleador. En el mismo período los jornaleros pasaron de 3,3 a 7,7 por empleador.
Es decir, el lento proceso de modernización del campo colombiano no ha producido ni una reducción de la población rural en términos absolutos, ni una reducción del número de campesinos. En cambio, miles de campesinos sin tierra han invadido los territorios indígenas para sembrar la coca y la amapola como única forma que les queda para subsistir.

Frente a tal realidad se enfrentó la visión de Lauchlin Currie sobre el desarrollo, que ha guiado los planes oficiales colombianos desde hace 45 años. Currie, ya fallecido, consideró siempre como una misión histórica, la ruptura de este modelo demográfico. El lema "sobra mucha gente en el campo y en la agricultura" se ha repetido desde entonces.

El economista "desarrollista", Edith Whethem consideraba que "la política apropiada para un gobierno que persigue la eficiencia económica consiste en estimular el éxodo de la agricultura y la consolidación de predios por todos los medios que no creen una conmoción política intolerable" (Whethem, 1960:97-98). En 1966 Currie recordaba la recomendación de John Coppock de reducir anualmente en 4\% el número de personas dedicadas a la agricultura, que para Colombia significaba 800 mil agricultores menos en diez años, número cercano al de los desplazados por la violencia entre 1987 y 1997

El propio Currie recomendaba un programa deliberado de movilidad acelerada para conseguir la suficiente emigración del campo y partiendo del análisis histórico sostenía que la guerra puede tomar el lugar de un programa de movilidad acelerada (Currie, 1968: 95). Por consiguiente, se oponía a que el problema agrario fuera resuelto convirtiendo a muchos pequeños agricultores en más eficientes y productivos, pues, según él, este método mantenía a "demasiada" gente en la agricultura (Currie, 1968: 86).

La visión de un campo "moderno" con grandes fincas capitalistas mecanizadas como eje del desarrollo nacional fue la clave que iluminó el Acuerdo de Chicoral y la clausura de la reforma agraria en la década de los setenta.

Pero los diferentes programas desarrollistas con los cuales se quiso "modernizar" el campo, reduciendo la población dedicada a la agricultura, no surtieron el efecto de modernizar, ni el de "limpiar" las tierras de campesinos. A pesar de las 393.648 parcelas que, según un estudio de la Compañía Colombiana de Datos realizado por Carlos Lemoin, perdieron los campesinos durante la Violencia de los cincuenta, la población de fuera de las cabeceras municipales pasó de 6 millones en 1938 a 7 millones en 1951, y a 8 millones 400 mil en 1964, en tanto que el número de trabajadores independientes dedicados a la agricultura pasó de 609 mil en 1938 a 719 mil en 1964.

En definitiva, se quiere "limpiar" el territorio de gente "ineficiente" o "sobrante" y lo están tratando de hacer mediante la guerra. No sólo hay desplazados porque hay guerra, sino especialmente hay guerra para que haya desplazados. Sin embargo, ni siquiera la Violencia pudo evitar el aumento de población rural y campesina.

Entender el carácter radical de este fenómeno, comprender lo que ha pasado en los últimos años y lo que pasa actualmente en el campo colombiano, sólo es posible si inscribimos todo el escenario que se ha presentado con los datos 
anteriores, en medio de la reestructuración impuesta a la economía colombiana y al sector rural en particular.

Lo que prima ahora en el país y en otras naciones es la perspectiva de la globalización del capital, la que dinamiza, frena y/o determina absolutamente todo. Y dentro de esa globalización, a la cual estamos siendo sometidos al igual que en el resto del mundo, a Colombia se le han asignado unos papeles que tienen que ver con algunas de sus características y, especialmente, con las necesidades del mercado mundial. Sabemos que existen unas prioridades dentro de las cuales no está contemplado el sector agropecuario tradicional.

El sector agropecuario es considerado, en la práctica y en los planes de desarrollo globales de las transnacionales, como totalmente subsidiario y complementario; donde lo único desarrollable sería la producción a gran escala, regida por grandes inversionistas, a quienes se supeditarían como "socios" (aparceros) los pequeños propietarios, especialmente en plantaciones de palma africana o explotaciones madereras, según el modelo de Malasia e Indonesia. Los proyectos agroindustriales y forestales, así concebidos, se articularían a los megaproyectos viales y de infraestructura para elevar, de esa manera, su rentabilidad, tal y como se ha promovido para el caso del río Meta, al cual se prevé privatizar.

Las ramas económicas prioritarias son, entonces, la exploración y explotación petroleras y mineras, las cuales se consideran asuntos fundamentales asignados a Colombia. También las telecomunicaciones y la infraestructura vial terrestre, marítima y fluvial.

Así, se ha realizado un desplazamiento calculado de población y se han tomado medidas legales e ilegales de orden expropiatorio, y se van a seguir tomando, en contra de los campesinos, indígenas, comunidades negras, en torno a lo que son los proyectos petroleros/mineros, los megaproyectos eléctricos o viales y los proyectos de exploración biológica y genética que se realizan en diferentes lugares del país.

El 13 de abril de 1999 se anunció la pronta apertura de la licitación para la concesión de navegación comercial y de puertos, en los ríos Atrato y Meta, alrededor de los cuales se han desplegado la violencia y el desplazamiento de población campesina y afroamericana, justo donde se sitúan los territorios indígenas Embera, Tule, Achagua, Piapoco, Sikuani, Saliva y Amorúa.

Hacia el futuro, cuatro proyectos viales terrestres-fluviales-portuarios deben ser especialmente mencionados:

A-El canal seco Atlántico-Pacífico (Atrato-Truandó) y sus conexiones con el ferrocarril Medellín-Buenaventura y las carreteras del Pacífico a Medellín y Pereira.

B- La carretera Urabá-Maracaibo (Venezuela).

C- La intercomunicación río Orinoco-río Meta-Buenaventura.

D-La intercomunicación río de La Plata-AmazonasNapo-Putumayo-Tumaco, con puerto fluvial y seco en Puerto Asís.

El canal seco que se llama Atlántico-Pacífico, de las vecindades del Atrato, es una prioridad porque está dentro del proceso global económico asignado a Colombia. Con anterioridad a la construcción de este canal se desarrolla un proceso expropiatorio, al igual que en las tierras de Córdoba y Cesar situadas sobre la proyectada autopista Urabá/ Maracaibo.

En el río Meta (Puerto López, Puerto Gaitán, Guaroa) se ha producido una masiva compra de tierras y la presencia de paramilitares financiados por los compradores, en tanto que la Asociación de Ganaderos de Puerto López amenazó en 1997, mediante carta, al Instituto Colombiano de Reforma Agraria Incora, diciendo que utilizaría las armas si se constituía una "Reserva Campesina" en el departamento del Meta. También ha comenzado el proceso de violencia en Puerto Asís.

Aunque hay millones de personas pobres, Colombia no tiene guerra por esa razón, sino porque hay riqueza. $Y$ es en torno a esa riqueza que se generan la violencia y el desplazamiento masivo.

No sólo la violencia ilegal sino también la ley se utiliza para este cometido. Por ejemplo, si se analiza el proyecto de ley de Código de Minas que presentó el tristemente célebre Doctor Rodrigo Villamizar, se ve que se trata de un proyecto de contrarreforma agraria, que autoriza al Ministerio de Minas a expedir títulos mineros cuya posesión permite decir a indígenas, campesinos o inclusive terratenientes, que siempre han vivido en el lugar, que ya no son los propietarios de la tierra. Como sabemos, el Estado es propietario del subsuelo, pero resulta que lo que se quita al campesino es el suelo.

Entonces, quienes se aterraban y argumentaban que no podía haber expropiación por vía administrativa para la reforma agraria, aprobaron en la Comisión Quinta de la Cámara de Representantes en 1997, una expropiación, ya no sólo por la vía administrativa, sino por la vía privada, ya que quien hace la expropiación es la empresa minera y no el Estado.

Si el campesino no negocia, el minero le entrega al alcalde una caución en la cual se incluye la compensación económica por daños que le tiene que dar al campesino y, sin más, se le saca por la fuerza. Éste, si quiere, tiene la posibilidad de reclamar después el depósito que dejó la empresa minera en la alcaldía del municipio. Eso no es otra cosa que la privatización de la expropiación, pero no para expropiar a los grandes propietarios sino para los campesinos, e incluso indígenas, pese a que la Constitución dice que los resguardos son inalienables.

Ese Código, que fue aprobado en primer debate de la Comisión Quinta de la Cámara de Representantes, ha logrado detenerse por el momento, gracias a una alianza de indígenas, campesinos, pequeños mineros y sindicatos que resume la verdad de lo que está pasando.

Aquí el derecho de propiedad no importa, porque es la propiedad de las comunidades indígenas o afroamericanas o de los campesinos lo que está en juego. Lo que priman son los intereses de las empresas mineras, como las que están del lado del Brasil esperando que se apruebe ese código Minero para entrar al Guainía y para obtener títulos mineros sobre los Resguardos indígenas.

Esa es la realidad. El Código de Minas, el vigente y el proyectado, tienen concordancia con otras normas ya aprobadas: las famosas zonas petroleras y zonas mineras, como 
la que se acaba de crear en el municipio de Maicao con 38 mil hectáreas, en el territorio del pueblo Wayúu. La ley 160 de 1994 le asigna competencia para crear las reservas mineras al INCORA, pero además lo esta haciendo sin consultar previamente a los indígenas, incumpliendo el Convenio 169 de la OIT.

Por otra parte, la ley de orden público ordenó la expropiación de toda propiedad campesina situada en las proximidades de un pozo petrolero. La Ley 160 de 1994 no sólo habla de pozos petroleros sino de cualquier recurso no renovable o vía importante. De este modo, si existe una cantera o un plan de carretera o canal, no pueden titular a cinco kilómetros a la redonda. Ese mandato, que está en la ley 160 , forma parte de la contrarreforma agraria, que ya se ha aplicado legalmente en Caño Limón y en Cusiana, e ilegalmente, afectando a cientos de miles de campesinos.

Ilegal es también la pretensión de Ecopetrol, el Ministerio de Minas y la OXY de imponer el límite del Resguardo indígena U'wa a cinco kilómetros del pozo de Gibraltar 1 que proyectan perforar en territorio del pueblo U'wa. Hasta el 25 de mayo de 1999, y tras tres años de haber culminado los estudios de ley, el Incora no ha podido definir los límites del Resguardo U'wa, por la imposición de las petroleras.

Luego, en Colombia y dentro de este esquema global, el valor e importancia de la tierra y la pelea y violencia que se dan en ella no se limitan a la vieja disputa entre los terratenientes y los campesinos e indígenas. Lo principal, ahora, estriba en que se enfrentan intereses estratégicos y territoriales, el acceso a recursos naturales y a vías terrestres o fluviales y a puertos y aeropuertos, o, lo que es lo mismo, la revalorización inmensa de los predios por causa de los macro-proyectos.

Vemos como, en los últimos dos años, se han agudizado los conflictos en el país, los desplazados, los ataques a las comunidades negras, los asesinatos de indígenas, las marchas campesinas e indígenas, los paros campesinos y sin embargo, se sigue haciendo oídos sordos a esa situación, e incumpliendo los compromisos con la gente.

Si no se cambia la óptica del presupuesto que se dedica a los campesinos, indígenas y comunidades negras y a la reforma agraria, el conflicto colombiano continuará agudizándose y, todos los que queremos una Colombia en paz, seguiremos sumidos en una guerra que se intensificará todavía más ante la sordera de los dirigentes del país, quienes siguen pensando únicamente en cómo beneficiarse de la globalización, en cómo quedar bien ubicados allí, olvidándose que "bajo la tierra se prepara la erupción de un volcán".

Los pueblos indígenas, las comunidades afroamericanas y los campesinos insistimos en construir algo así como polders, como los holandeses, es decir en "ganarle terrenos propios al océano de la globalización y a la concentración de la propiedad". Tenemos una inmensa violencia en frente, pero no vamos por ello a renunciar a la lucha.

En medio de esta situación acudimos a la solidaridad internacional. Es evidente que la inversión transnacional está cumpliendo un papel primordial en la dinámica colombiana y es necesario que se tome conciencia de que no es ético invertir y llenarse de dólares los bolsillos a costa de la muerte de los colombianos. Las normas internacionales debieran impedir las inversiones causantes de violencia y daños a la naturaleza.

Por años, las transnacionales petroleras Exxon, Mobil, Texaco, Shell, Oxy y BP se han hecho presentes en zonas donde se desencadena la violencia contra los campesinos y el etnocidio de los indígenas.

Recordamos que la primera explotación petrolera llevada a cabo en el país por la Standard Oil (hoy Exxon), en Barrancabermeja, exterminó al pueblo indígena Yariguí. En territorio vecino operaron la Shell y la Texas cuya explotación exterminó a los Aripí. Los hermanos Barí, vecinos de los U'wa y Chibchas como ellos, a pesar de su resistencia con flechas fueron invadidos por la Mobil, la Gulf y la Texas y perdieron la mitad de su población y las dos terceras partes de su territorio. Los Kofán del Putumayo perdieron el $80 \%$ de su territorio y la mitad de su población por la invasión de la Texas. Y en Caño Limón, Arauca, la invasión de la Occidental y la Shell cambió el régimen de aguas del área y convirtió a los Hitnu (Macaguanes), Hitanu (Iguanitos) y a los Sikuani (Guahibo) del área, en los indígenas más pobres de Colombia, llevándoles a la miseria.

Recientemente, también la construcción de la represa hidroeléctrica de Urrá 1, por una empresa sueca con infraestructuras rusas y financiación sueca y canadiense, ha traído la destrucción y la violencia contra los indígenas. La pesca en el río Sinú se acabó y los Embera Katío de Tierralta han perdido su fuente de sustento.

Dos personas que denunciaron el impacto ambiental de la represa han sido asesinados: Alberto Alzate y Mario Calderón. El más querido anciano líder de los Emberá Katío de Tierralta, Alonso Domicó Jarupia, fue asesinado por los paramilitares de las Autodefensas de Córdoba y Urabá el 25 de agosto de 1998, después de que la Corte Constitucional ordenó impedir la inundación de la represa por una acción judicial de tutela interpuesta por los Cabildos Indígenas de los ríos Sinú y Verde. En enero de 1999 amenazaron con ejecutar masacres en las comunidades de Kiparadó, Widó y Pavarandó en los ríos Sinú, Esmeralda y Verde.

La empresa Urrá S.A. se demoró tres meses en comenzar a cumplir el fallo de la Corte Constitucional. Tiempo durante el cual, asesores de los indígenas debieron exiliarse por amenazas. El 28 de marzo los pescadores no indígenas del río Sinú también ganaron una tutela a Urrá S.A. Los dirigentes de una ONG que les colabora, la Fundación Nuevo Arco Iris, han sido amenazados. El 24 de abril de 1999 asesinaron a Lucindo Domicó, principal negociador de los Cabildos de los ríos Sinú y Verde frente a Urrá S.A. Lucindo alquiló una habitación en Tierralta para poder participar en la negociación que la Corte impuso a la empresa, pero allí fue asesinado y la empresa sigue eludiendo la negociación con los dos Cabildos.

El Gobierno de Colombia ha pedido el apoyo de Japón para el megaproyecto del río Meta, que amenaza a los indígenas y que ha estado precedido por el desplazamiento masivo de los campesinos de la región. Japón ha contestado que invertirá en el río Meta cuando haya paz. Es una decisión juiciosa pero insuficiente, pues, la "paz" puede venir, o de un tratado o de una imposición violenta de condiciones de seguridad para los inversionistas, pero no necesariamente 
incluirá la conveniencia de las comunidades locales indígenas o campesinas.

Lo que la solidaridad internacional tiene que exigir es algo más y algo diferente de la "seguridad" para las inversiones. Es necesario exigir que toda inversión en Colombia reúna por lo menos tres requisitos:

1- El fundamental: Concertar con las comunidades locales campesinas, afroamericanas e indígenas para que éstas tengan un papel decisorio en la elaboración y aplicación de los planes, con lo que se les garantice que realmente van a ser beneficiadas y no se lesionarán su integridad social, económica y cultural.

2- Garantizar, también, que no se producirán daños graves al medio ambiente y a los ecosistemas, compensándose todo impacto ambiental negativo.

3- Garantizar la vigencia de los derechos humanos; los derechos de propiedad colectivos e individuales de los campesinos, afroamericanos e indígenas y los derechos laborales de los trabajadores de los proyectos, impidiendo que se acuda a métodos violentos o de coacción contra la población.

Los inversionistas internacionales han tenido una responsabilidad o, mejor dicho, una irresponsabilidad frente a la violencia en Colombia. Es de esperar que ahora la solida- ridad internacional con el pueblo colombiano les obligue a ser responsables con la concertación de la paz.

Una muestra de una nueva responsabilidad internacional con Colombia será una modificación de los tratados internacionales que atan al país a la libre importación de alimentos, multiplicada por ocho en esta década, abriendo el paso a nuevos tratados comerciales, combinados con proyectos de sustitución de cultivos ilegales y planes de reforma agraria integral, como la multiplicación de las zonas de Reserva Campesina, donde se limite el tamaño y el comercio de la propiedad a unidades campesinas, que se articulen mediante planes de desarrollo y se puedan entregar, así, a los campesinos las 5 millones de hectáreas agrícolas ahora subutilizadas.

Se trata de concertar nuevas políticas internacionales y nacionales que permitan a Colombia sustituir la economía del narcotráfico y encaminarse por caminos de paz, bienestar, calidad de vida y diversidad cultural, social y económica.

\section{BIBLIOGRAFÍA}

Whethem, Edith (1960): The Economic Background to Agricultural Policy. London: Cambridge University Press.

Currie, Lauchlin (1968): Desarrollo Económico Acelerado. México: F.C.E.

\section{RESUMEN}

El autor plantea la necesidad de repensar el destino y los objetivos de las inversiones internacionales realizadas durante los últimos años en Colombia. Como indica Modragón, se ha asistido a un desplazamiento de las comunidades indígenas, afroamericanas y de campesinos pobres de los suelos más fértiles, que se ha correspondido con un proceso de reconcentración de la propiedad agraria, así como un creciente interés por parte del capital extranjero en los recursos naturales de estas áreas. En este sentido, el artículo plantea nuevos requisitos para las inversiones internacionales: la necesaria participación de estas comunidades en las decisiones, el respeto al medio ambiente y la vigencia de los Derechos Humanos.

Palabras clave: comunidades indígenas, afroamericanas y campesinas, propiedad agraria, inversiones internacionales, violencia, paz.

\section{ABSTRACT}

The author analyzes the requeriment of rethinking the objectives and goals of inversions in Colombia during the last years. As Mondragon indicates, there has been a displacement of indigenous, afroamericans and poor peasants communities from the most fertile lands, followed by a process of reconcentration of agrarian properties, and a growing interest from foreign investors in the natural resources of these areas, specially oil. In this sense, the articles sets new requeriments for the international investements: the necessary participation of these communities in the decision-making process, the respect of environment and Human Rights.

Key words: indigenous, afroamerican and poor peasants communities, agrarian property, international inversions, violence, peace. 